\title{
Double-Layer Membrane Cathode with Improved Oxygen Diffusivity in Zinc-Air Batteries
}

\author{
Arturo Reza Ugalde and Hani E. Naguib \\ Version Post-print/Accepted Manuscript \\ Citation Ugalde, Arturo Reza, and Hani E. Naguib. "Double-layer membrane \\ (published version) cathode with improved oxygen diffusivity in zinc-air batteries." Energy \\ Storage Materials 8 (2017): 1-9. Doi: 10.1016/j.ensm.2017.03.009 \\ Copyright/License \\ (c) (1) $\Theta$ This work is licensed under the Creative Commons \\ Attribution-NonCommercial-NoDerivatives 4.0 \\ International License. To view a copy of this license, visit \\ http://creativecommons.org/licenses/by-nc-nd/4.0/.
}

How to cite TSpace items

Always cite the published version, so the author(s) will receive recognition through services that track citation counts, e.g. Scopus. If you need to cite the page number of the author manuscript from TSpace because you cannot access the published version, then cite the TSpace version in addition to the published version using the permanent URI (handle) found on the record page.

This article was made openly accessible by $U$ of $T$ Faculty. Please tell us how this access benefits you. Your story matters. 


\title{
Double-Layer Membrane Cathode with Improved Oxygen Diffusivity in Zinc-Air Batteries
}

\author{
Abstract \\ The commercialization of portable zinc-air batteries has been limited to the coin cell shape, \\ mainly due to issues related to the cathode morphology. These types of batteries commonly use \\ an aqueous electrolyte, which is susceptible to changes in air temperature and humidity that can \\ cause leakage and block the air-cathode. This problem entails the use of bulky systems that \\ require an empty gap between the porous cathode and the electrolyte to avoid flooding. This \\ paper presents a novel fabrication method and morphology for a conductive and flexible double- \\ membrane nanocomposite air-cathode. The pore morphology for each membrane was designed \\ for two purposes using two different foaming techniques. The foaming technique includes \\ supercritical $\mathrm{CO}_{2}$ in a high-pressure chamber to create a hydrophobic closed-cell structure. On \\ the other hand, $\mathrm{NaCl}$ was used as a temporary space-holder to create a hydrophilic open-cell \\ morphology. The closed-cell membrane presented an optimal performance as a hydrophobic \\ oxygen diffusion layer whereas the hydrophilic open-cell membrane, apart from increasing the \\ catalytic surface area, also increased the water absorption by 12 times with a swelling capacity of \\ $68 \%$. The electrochemical tests exhibited stable performance without presenting leaking even \\ when bent under a relative humidity of $85-90 \%$. The specific energy density achieved was as \\ high as $198 \mathrm{~W} \mathrm{~h} \mathrm{~kg}^{-1}$, which is similar to that of some of the available commercial alkaline cells. \\ Furthermore, the double-membrane air-cathode also has the advantages of low cost, high \\ recyclability and the possibility of multiple configurations including flexibility for both primary \\ and secondary configurations.
}




\section{Introduction}

Today's electronics market continues to grow at a considerable rate. The necessity of energy storage systems that fulfill power requirements for new devices has produced continuous research into new materials for electrochemical cells with higher energy density and that are low-cost, safe to use, and have high recyclability. Nowadays, Li-ion batteries govern the market due to their high-energy density. However, such batteries are nearing their capacity limit, which is insufficient in supporting the actual demand for low-cost batteries with high energy density [1]. Also, safety problems (i.e., thermal runaway and flammability) restrict their usage for the new generation of electronic devices [2].

From different storage systems that have been previously explored, the metal-air battery is one of the most promising due to its high theoretical specific energy (around $1300 \mathrm{~W} \mathrm{~h} \mathrm{~kg}^{-1}$ for zinc), inexpensive materials, and high recyclability [2-4]. Since oxygen is used as the cathode and can be absorbed from air, the battery can be filled with a greater amount of active material, which significantly increases its capacity. Among metal-air batteries, the Zn-air battery has attracted more attention due to some advantages, such as its use of environmentally friendly materials, its low-cost fabrication process, and the possibility to build an electrically rechargeable cell. However, although the Zn-battery has reached the market of primary cells, its commercialization has been narrowed to the coin-cell configuration with a limited specific energy due to issues related mainly to the inefficient cathode materials used for its fabrication [5].

The air-electrode (cathode) in the metal-air battery consists of a porous material (usually carbonbased) that is designed to supply oxygen from the air to the battery. The oxygen is then reduced by a chemical reaction through the electrolyte [6-10]. One of the main problems related to the aircathode is the effectiveness of its morphology for an optimal oxygen diffusion and to provide 
enough surface area for the triple phase boundary, where the oxygen reduction reaction (ORR) takes place. This problem is reflected directly in the energy density and the overall cell performance.

To better understand the role of the air-cathode during the zinc-air battery discharge, the following process occurs:

At the cathode, the oxygen absorbed from the air due to a difference in pressure is reduced at the three-phase contact (electrolyte, catalyst, and oxygen) with the help of the catalyst. The reaction produces hydroxyl ions which migrate to the anode through the electrolyte to form zincate and a potential of $0.4 \mathrm{~V}$ (Equation 1).

$\mathrm{O}_{2}+2 \mathrm{H}_{2} \mathrm{O}+4 e^{-} \rightarrow 4 \mathrm{OH}^{-}\left(E^{0}=0.4 \mathrm{~V}\right)$

At the anode, upon battery discharge, oxidation of zinc produces soluble zincate ions $\left(\mathrm{Zn}(\mathrm{OH})_{4}^{2-}\right)($ Equation 2). Later, zincate ions decompose to insoluble zinc oxide and water (Equation 3) [10].

$\mathrm{Zn}+4 \mathrm{OH}^{-} \rightarrow \mathrm{Zn}(\mathrm{OH})_{4}^{2-}+2 e^{-}\left(E^{0}=-1.25 \mathrm{~V}\right)$

$\mathrm{Zn}(\mathrm{OH})_{4}^{2-} \rightarrow \mathrm{ZnO}+\mathrm{H}_{2} \mathrm{O}+2 \mathrm{OH}^{-}$

The overall reaction produces $1.65 \mathrm{~V}$ (Equation 4)

$2 \mathrm{Zn}+\mathrm{O}_{2} \rightarrow 2 \mathrm{ZnO}\left(E^{0}=1.65 \mathrm{~V}\right)$

Another of the main problems for the air-cathode is related to the accumulation of the water produced during the reaction, which accelerates the degradation of the electrolyte and induces flooding at the gas diffusion cathode; also, another reaction between water and zinc occurs, resulting in hydrogen gas generation that causes severe corrosion of the metal anode (Equation 5) $[11-16]$

$\mathrm{Zn}+2 \mathrm{H}_{2} \mathrm{O} \rightarrow \mathrm{Zn}(\mathrm{OH})_{2}+\mathrm{H}_{2} \uparrow$ 
Apart from the water accumulation in the electrolyte due to the chemical reaction, $\mathrm{Zn} / \mathrm{Al}$-air batteries are vulnerable to environmental conditions. This type of batteries commonly uses alkaline aqueous electrolytes due to their high ionic conductivity and high solubility to electrode reaction products [17]. However, this type of electrolytes (including aqueous-gel electrolytes) is extremely susceptible to air humidity and temperature and can generate flooding at the air-cathode. This situation increases the concentration polarization at the electrode, which relates the loss of energy due to the inefficient mass transfer originated by the low oxygen diffusion [7]. Although a lot of effort has been done in an attempt to develop an efficient non-aqueous electrolyte, the high ionic conductivity of aqueous electrolytes entails their use for hybrid electrolytes in modern systems. Moreover, new configurations for metal-air electrochemical cells are designed to be thinner and more flexible in order to increase the range of applications for wearables or modern devices [18]; this only exacerbates the flooding problem.

Therefore, a well-designed air-cathode with the right balance between hydrophobicity, hydrophilicity, and porosity control is critical [19]. The air-electrode must also be electrochemically stable and capable of avoiding the electrolyte loss of water without affecting the gas diffusion towards the cell.

Different studies have been carried out to improve the gas diffusivity towards the cell to avoid the flooding problem. Most of the methods consist of multiple carbon layers with a current collector that give a natural but uncontrolled porosity. While one part of the electrode is submerged in the electrolyte, the other section that is closed to the electrode surface (in contact with the atmosphere) is treated with polytetrafluoroethylene (PTFE) to achieve the hydrophobicity [10]. The issues with such a method are related to pore size control and pore density control as well as achieving the right amount and deposition of PTFE without affecting 
the oxygen diffusion. Furthermore, although this configuration might prevent the water from going into the gas diffusion section, the water generated in the electrolyte will still accumulate in the electrolyte. This accelerates the corrosion rate at the anode and reduces the cell efficiency. On the other hand, studies focused on the development of electrodes for flexible $\mathrm{Zn}$-air batteries have been increasing rapidly. Zhang et al., 2016 [20], reported a bifunctional air-electrode with a flexible wire-shaped structure. The system presents high mechanical properties and cyclability by combining a conducting polymer (polypyrrole), carbon nanofibers and cobalt nitride $\left(\mathrm{Co}_{4} \mathrm{~N}\right)$. Another example of modern methods (e.g., Xin-Bo Zhang et al. [21]) present novel techniques to fabricate flexible electrodes with controlled porosity for metal-air batteries. In this work, a method inspired by golden-toad eggs is developed to achieve a flexible carbon fiber electrode with interconnected channels to facilitate mass transport in $\mathrm{LiO}_{2}$ batteries. Also, Yao et al., [5] developed a flexible carbon-based film as a bifunctional catalyst for Zn-air batteries; however, any of the methods previously mentioned present a suitable solution to reduce the problem of flooding at the air-cathode and improve the oxygen diffusivity.

This paper presents a novel and flexible double-layer membrane air-cathode for $\mathrm{Zn} / \mathrm{Al}$-air batteries combining two different membranes with an independent pore morphology for each one. A thermoplastic hydrophilic membrane with an open-cell morphology is used for water absorption, and a hydrophobic membrane with a closed-cell morphology is used as a gas diffusion layer. This not only solves the problem of flooding at the gas diffusion layer due to the use of aqueous electrolyte, but it also increases the surface area for catalytic activity and achieves a flexible configuration in order to expand available manufacturing options. In this paper, the fabrication method and the electrochemical characterization are explained in detail as well as the results and conclusion. The composite membrane is made of thermoplastic polyurethane (TPU) as a matrix 
and multiwall carbon nanotubes (MWCNT) / active carbon (AC) as fillers for electrical conductivity and catalytic activity [22,23]. Studies have demonstrated the high capacity of TPU matrix for containing a significant amount of CNT due to the soft polymer structure. [24,25]. Two different foaming techniques were considered to control the pore morphology for each membrane: a batch-foaming process using supercritical $\mathrm{CO}_{2}$ in a sealed high-pressure chamber for the closedcell morphology; and $\mathrm{NaCl}$ as a temporary space holder for the open-cell morphology. The hydrophilic open-cell pore structure must be designed to induce a capillarity effect between the matrix and the electrolyte, facilitating the water absorption stored in the electrolyte. Figure 1 presents the concept proposed for the flexible $\mathrm{Zn} / \mathrm{Al}$-air battery. It consists of the double-layer membrane air-cathode, a 4M $\mathrm{KOH}$ solid state electrolyte, and finally the metal anode. The fabrication method allows customization of the materials - for example, the polymer matrix or fillers can be changed according to specific requirements in terms of mechanical properties or electrochemical behavior. In this work, simple active carbon was used as the catalyst to improve the ORR; however, a bifunctional catalyst can be used instead, applying the same fabrication technique. The fabrication method and material used provide high recyclability and wider options for multiple shape fabrication, including mechanically flexible batteries.

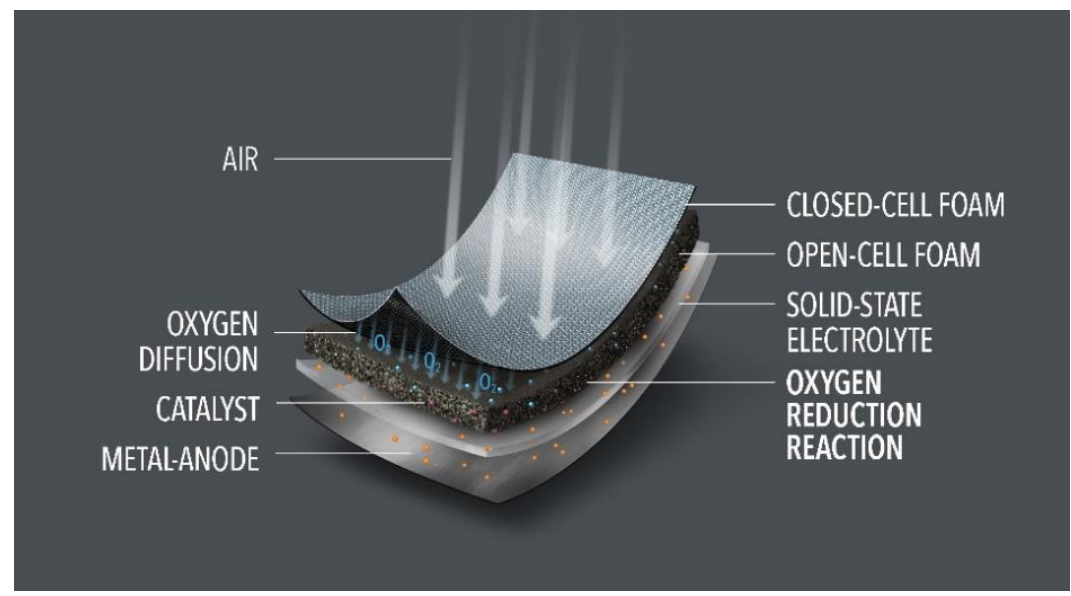

Figure 1. Flexible metal-air battery concept 


\section{Experimentation}

The experimentation was divided mainly into three parts: membrane fabrication, wetting properties and swelling capacity of the membranes, and electrochemical tests.

\subsection{Material}

Since the purpose of the battery is to be flexible, each part was made from thin films. For the anode, aluminum 1100 and commercial zinc (99\%) sheets from McMaster-Carr were used first; then, the metal zinc sheet was replaced with zinc powder in order to achieve higher surface area [26]. The anode metal sheets' dimensions are $1 \mathrm{~cm} \mathrm{x} 1 \mathrm{~cm} \mathrm{x} \mathrm{.2} \mathrm{mm} \mathrm{(width,} \mathrm{depth,} \mathrm{height,}$ respectively). The aluminum sheet metal weight was $0.20 \mathrm{~g}$, and the zinc's weight was $0.6 \mathrm{~g}$. The cathode is a composite of TPU, AC, and MWCNT. 10-20 nm MWCT made by CCVD (catalytic chemical vapor deposition), purified and functionalized using concentrated acid chemistry, were supplied by Cheap Tubes Inc. (Cambridgeport USA). The AC was supplied by AquaTech with an approximate grain size of 2-7 mm. The TPU was supplied by Covestro (Desmopan $385 \mathrm{E}$, 300-grade series, ester / Shore hardness A 85 - 89). Reagent grade sodium chloride for physical foaming with +80 mesh particle size was supplied from Sigma-Aldrich. The electrolyte is a 1mm solid-state layer made of PVA and $4 \mathrm{M}$ concentration $\mathrm{KOH}$. For the zinc powder, the PVA and $\mathrm{KOH}$ compound was mixed with the zinc powder to create a solid paste.

\subsection{Electrolyte}

The solid-state electrolyte is a compound of PVA/KOH. Two beakers were prepared with $25 \mathrm{ml}$ of deionized water; the first beaker was used to dissolve $\mathrm{KOH}$ pellets for a $4 \mathrm{M}$ concentration, and the second beaker was heated up to dissolve the PVA. The solution was magnetically stirred 
until the PVA powder was fully dissolved, then the $\mathrm{KOH}$ was added. The final PVA/KOH liquid electrolyte was poured in a flat plate and dried at ambient temperature and relative humidity of $35 \%$ for $24 \mathrm{~h}$. The result was a solid electrolyte film with a thickness of $0.1 \mathrm{~mm}$ (Figure 2a).

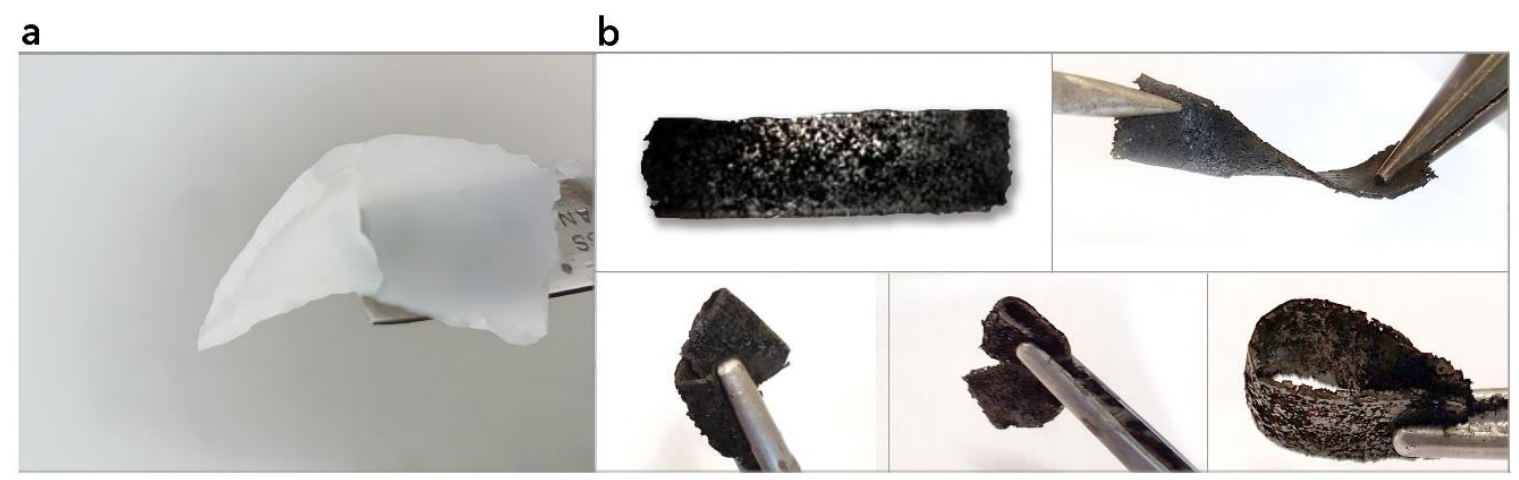

Figure 2. a) Flexible PVA/KOH solid-state electrolyte; b) Flexible composite membrane

\subsection{Open-cell foam}

For the hydrophilic layer, the TPU powder was blended with $60 \%$ wt. of $\mathrm{NaCl}$ to make a fine mix powder and achieve an open-cell morphology foam. $10 \%$ wt. of AC was ground into small particles ranging from 10 to $50 \mu \mathrm{m}$ and added to the TPU/NaCl powder. Finally, $10 \%$ wt. of MWCT were first sonicated with isopropyl alcohol for $20 \mathrm{~min}$. and then dried until the isopropyl alcohol was fully evaporated. Since the surface molecules of CNT's possess an extremely high intermolecular Van der Waals force of attraction, their dispersion in any type of matrix is commonly an issue. The sonication process helps to disperse the fillers in the solution, creating a thin CNT film once the alcohol is evaporated. Such a layer is more easily handled during the mixing process with the TPU powder. The TPU/NaCl/AC mix was added to the previous MWCTs concentration and stirred until the mix was completely homogeneous. 
A mold with the electrode's dimensions of $1 \mathrm{~cm} \mathrm{x} 3 \mathrm{~cm} \times 0.5 \mathrm{~mm}$ (width, depth, height, respectively) was filled with the mix previously prepared and then set in the compression mold at $190{ }^{\circ} \mathrm{C}$ for 30 min (Figure 3a). The mold with the melted compound was quenched in water to solidify the TPU. The solid and flexible electrode was submerged in water for $24 \mathrm{~h}$ to dissolve the $\mathrm{NaCl}$ particles, and then it was dried in an oven for $4 \mathrm{~h}$ at $70{ }^{\circ} \mathrm{C}$ (Figure $3 \mathrm{~b}$ ).

The result was a solid and flexible electrode with a micro-sized open-cell foam structure (Figure 3c). The $\mathrm{NaCl}$ dissolution formed interconnected channels within the matrix with the capacity to increase the capillarity effect between the electrode and the electrolyte. This morphology not only induces the electrolyte absorption in case leaking is present, but the open-cell structure also increases the catalytic activity for the MWCNT and AC.

a

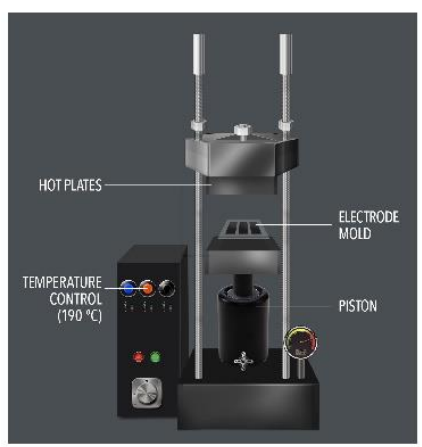

Compression Mold b

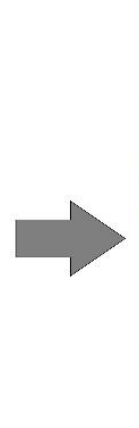

Salt Dissolution
C

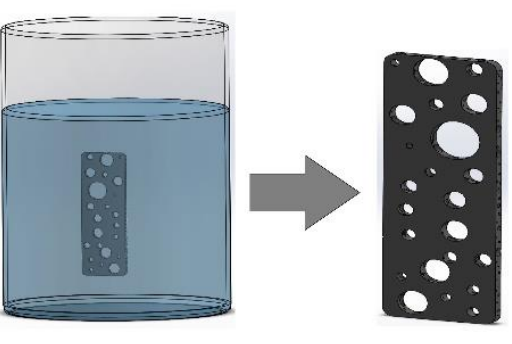

Open-Cell Foam

Figure 3. Scheme of the open-cell foam electrode preparation; a) Compression mold for electrodes fabrication; b) $\mathrm{NaCl}$ particles dissolution; c) Open-cell morphology

\subsection{Closed-cell foam}

For the hydrophobic layer, the process of preparation was the same as the one described for the hydrophilic layer, except for the addition of $\mathrm{NaCl}$. Also, the mold dimensions changed to $1 \mathrm{~cm} \mathrm{x}$ $3 \mathrm{~cm} \times 0.3 \mathrm{~mm}$. After the compression molding process, a batch-foaming process was performed to obtain the closed-cell foam morphology. During the batch-foaming process, a sealed high- 
pressure chamber was used to induce the cellular structure within the membranes (Figure 4d), where supercritical $\mathrm{CO}_{2}$ was injected at $2500 \mathrm{psi}(17.23 \mathrm{MPa})$ at standard ambient temperature for $3 \mathrm{~h}$ (Figure 4a). After the dissolution and saturation of the $\mathrm{CO}_{2}$ into the sample for $3 \mathrm{~h}$ (Figure 4b), the gas pressure was released, producing the pore nucleation within the sample matrix. The electrode was then taken out of the chamber and quenched in silicone oil at $100{ }^{\circ} \mathrm{C}$ for one minute (Figure 4c). The drastic increment in temperature reduces the solubility of the gas and softens the polymer, allowing the pore to expand (Figure 4e). After the silicone oil bath, the cell morphology of the samples was stabilized by cooling down the samples using cold water [2729]. Finally, the closed-cell foam was washed to remove the rest of silicone oil and dried in an oven for $4 \mathrm{~h}$ at $70{ }^{\circ} \mathrm{C}$. Both layers (i.e., the open-cell and closed-cell foam) presented high elasticity (Figure 2b).

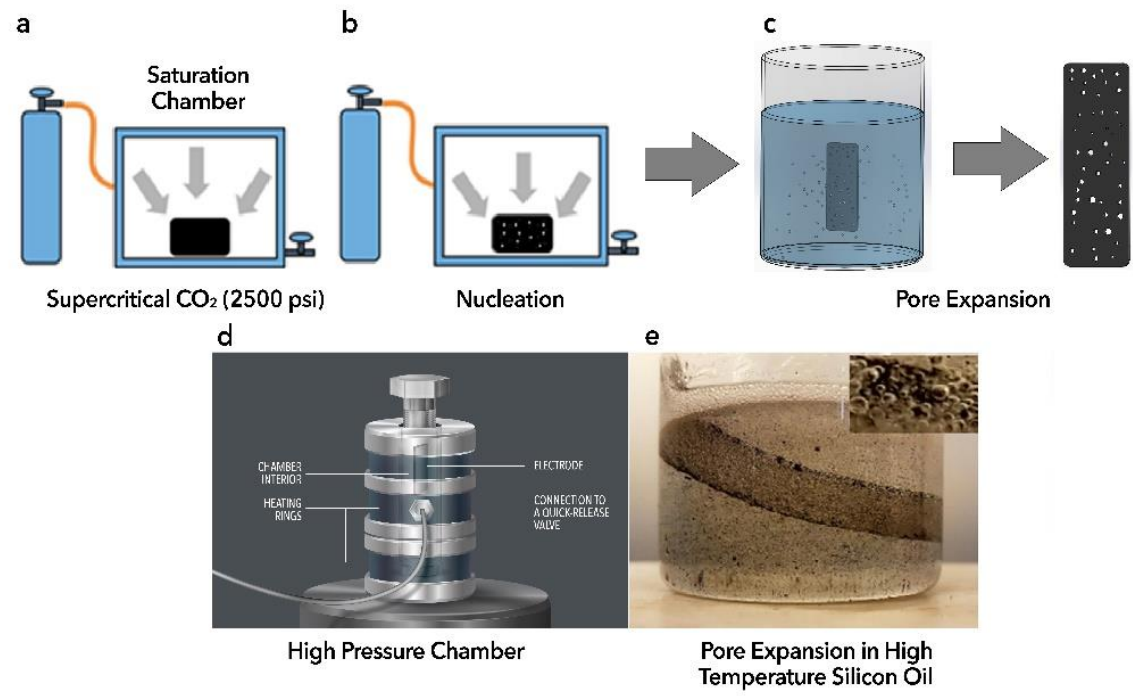

Figure 4. Scheme of the closed-cell foam electrode preparation; a) Supercritical $\mathrm{CO}_{2}$ injected at high-pressure into the chamber; b) Pore nucleation; c) Pore expansion; d) Diagram of high-pressure chamber; e) Electrode inside the high-temperature silicone oil

\subsection{Wettability and MVTR (moisture vapor transmission rate)}


To provide information about the membrane behavior with regards to water, wettability properties, swelling capacity, and MVTR were characterized using three different techniques. Wetting properties were measured using the telescope-goniometer technique. A $20 \mu \mathrm{L}$ water droplet was deposited on the surface of the sample, and the tangent angle at the three-phase contact was observed [30]. The swelling properties were examined by measuring and comparing the water-absorption capacity [31]. First, the hydrophilic membrane was immersed in deionized water for $72 \mathrm{~h}$ and weighed afterwards. The swelling capacity was calculated using the equation 6:

$\%$ Swelling $=[($ Wet weight - dry weight $) /$ dry weight $]$ X 100

MVTR by a continuous gravimetric control experiment was carried out with the purpose of measuring how much vapor-water the open-cell membrane is capable to absorb under hightemperature conditions. The experiment was done by measuring the water loss in a closed chamber at $50{ }^{\circ} \mathrm{C}$ using the membranes as a permeable outlet. First, only the gas diffusion membrane (closed-cell membrane) was used; second, both layers (open-cell membrane and closed-cell membrane) were used together as the permeable outlet for the chamber. The percentage of water lost was recorded every $2 \mathrm{~h}$ for $24 \mathrm{~h}$.

\subsection{Electrical conductivity and electrochemical test}

The electrical conductivity was characterized for both membranes separately using Novocontrol dielectric analyzer equipment. The samples were prepared by cutting the membranes into a circular shape with a diameter of $20 \mathrm{~mm}$. The experiment was conducted by applying an AC voltage of $1 \mathrm{~V}$ RMS (root mean square) to the samples throughout two copper plates under a frequency range of $0 \mathrm{~Hz}$ to $300 \mathrm{kHz}$. 
For the electrochemical tests, a Multi-Potentiostat Solartron analytical 1400 equipment was used. First, 0.2 and $0.5 \mathrm{~g}$ of aluminum and zinc metal sheets, respectively, that were $0.2 \mathrm{~mm}$ thick were used as the anode with the double-layer composite electrode as cathode and the solid-state electrolyte. Since an aluminum-air battery can only be used as a primary cell, and it can only be mechanically rechargeable by replacing the metal, the second test was performed just for the zinc anode due to the possibility of building the cell as a secondary battery (electrically rechargeable). For this test, $0.20 \mathrm{~g}$ of zinc powder was used as the anode with particles ranging from $100 \mu \mathrm{m}$ to $150 \mu \mathrm{m}$ of size in combination with the solid-state electrolyte.

No considerations for $\mathrm{CO}_{2}$ filtrations were taken. The electrochemical tests were performed under standard ambient temperature and pressure and a relative humidity ranging between $85 \%$ and $90 \%$.

\section{Results and discussion}

\subsection{ESEM images}

QUANT A FEG ESEM equipment was used to analyze and compare the internal morphology of the membranes. Figure 5a shows the open-cell structure generated by the dissolution of the fine $\mathrm{NaCl}$ particles. The morphology created is undefined with interconnected channels ranging from approximately 5 to $50 \mu \mathrm{m}$ throughout the matrix. Figures $5 \mathrm{~b}$ and $5 \mathrm{c}$ exhibit the CNT dispersion over the open-cell morphology, where CNTs in combination with the AC particles formed networks throughout the matrix and channels. On the other hand, Figure $5 \mathrm{~d}$ exhibits the internal closed-cell architecture of the membrane produced by the batch-foaming technique. It is possible to appreciate the high pore density and circular shape pores all over the matrix. Figures $5 e$ and $5 f$ show the well-defined pore structure with diameters ranging from 1 to $10 \mu \mathrm{m}$. 
It is important to highlight that, although the matrix after foaming is low in density $\left(1.2 \mathrm{~g} \mathrm{~cm}^{-3}\right.$

for TPU before foaming process, $0.93 \mathrm{~g} \mathrm{~cm}^{-3}$ for the closed-cell membrane, and $0.6 \mathrm{~g} \mathrm{~cm}^{-3}$ for the open-cell membrane), the TPU/CNT composite is flexible and strong enough to withstand bending.
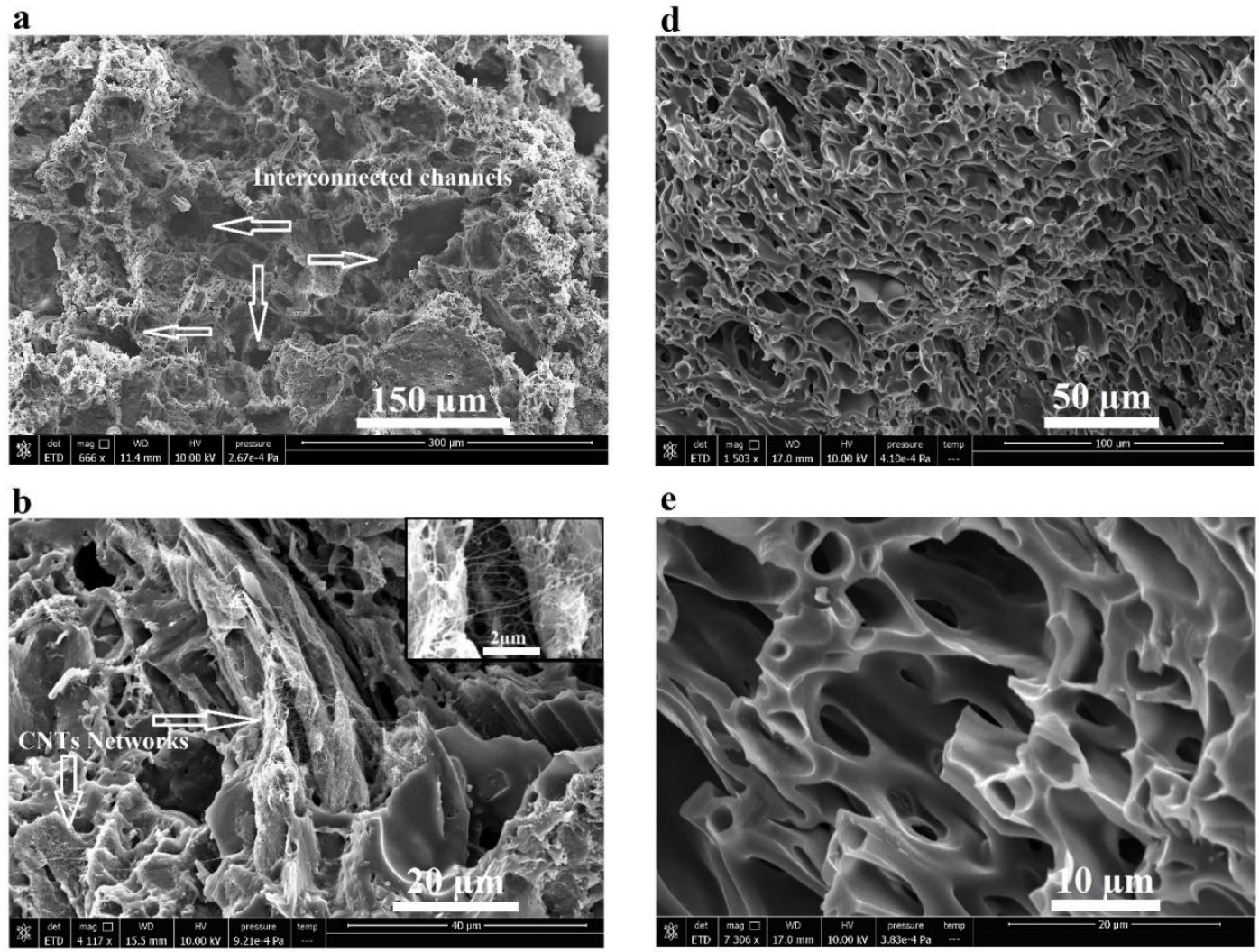

e
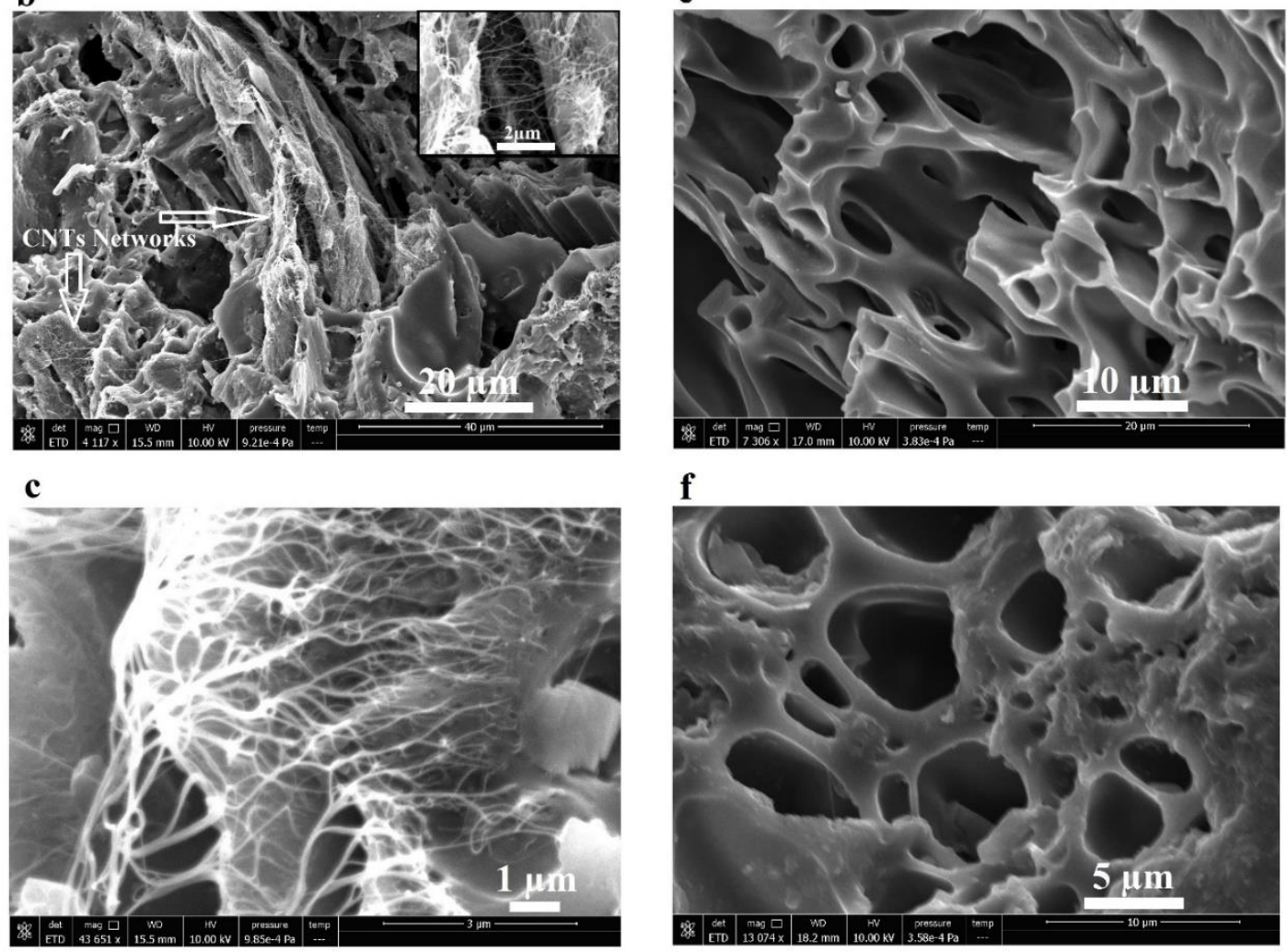

Figure 5. ESEM images a) Undefined open-cell morphology; b) CNTs network formed within the open-cell membrane, c) CNTs attached to TPU matrix; d) Closed-cell morphology; e and f) Well-defined pore structure with a diameter ranging from 1 to $10 \mu \mathrm{m}$. 


\subsection{Wettability, swelling capacity, and MVTR}

Figure 6 exhibits the contact angle for both membranes. Contrary to the contact angle that can be expected on a flat and smooth surface where the contact between the liquid and the solid is uniform, in the case of a porous surface, a wetting transition exists. As shown in Figure 6a, the contact angle between the surface and the droplet is $73^{\circ}$; however, this contact angle is due to an equilibrium formed between the air inside the pores and the liquid. Although this apparent surface presents low hydrophobicity, after 20 min of being suspended on the surface, the equilibrium between the water and the air trapped in the pores started to change and produced water diffusion into the channels; this reduced the contact angle up to approximately $33^{\circ}$ (Figure 6b). This effect also represents the capillarity effect between the liquid and the interconnected channels within the matrix. On the other hand, for the closed-cell membrane, a contact angle of approximately $130^{\circ}$ was observed, which denotes high hydrophobicity (Figure 6c). Although the membrane also possesses a porous morphology, the foam cell structure is smaller with a welldefined pore, which helps to maintain the equilibrium between the surface and the liquid and reduces the wettability.

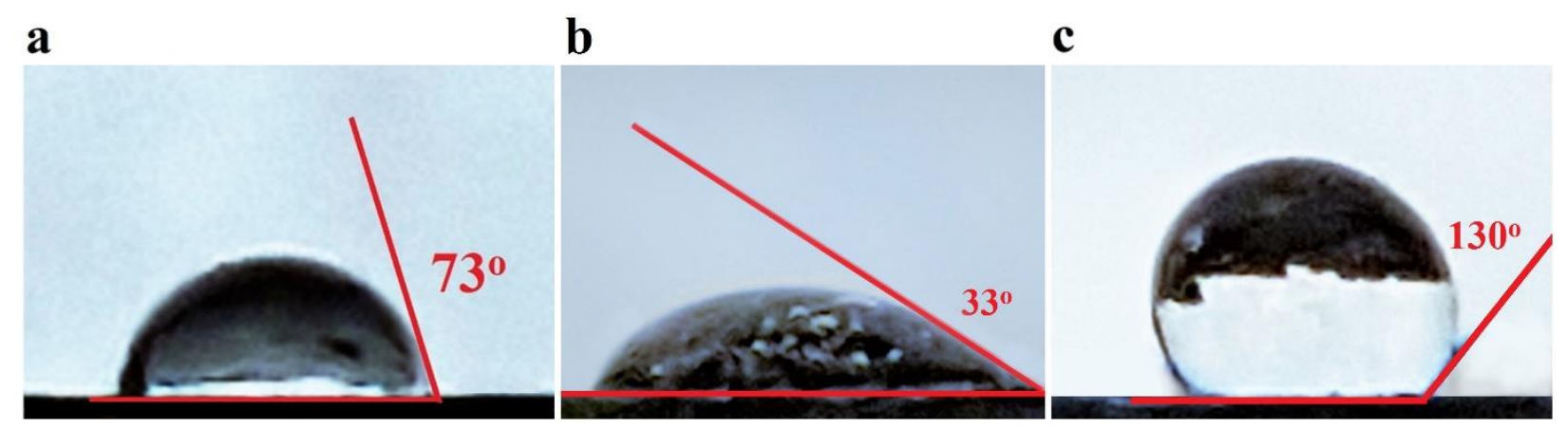

Figure 6. Contact angle pictures. a) Open-cell membrane; b) Open-cell membrane after 20 minutes; c) Closed-cell membrane.

For the swelling capacity characterization, the weight for the open-cell membrane before the immersion in water was $100 \mathrm{mg}$; after the $72 \mathrm{~h}$, the weight increased to $168 \mathrm{mg}$. By substituting 
the values in Equation 6, the results obtained for the swelling capacity was $68 \%$, whereas the closed-cell membrane presented a swelling capacity of only $4.4 \%$ (almost 12 times lower). This relates the hydrophilicity of TPU in combination with the internal open-cell morphology. Figure 7a displays the comparison of swelling capacity for both open-cell and closed-cell membranes with respect to the composite without foaming treatment. On the other hand, the MVTR process is divided into three steps: permeation/saturation, diffusion, and desorption. In Figure $7 b$, it is possible to appreciate the difference in the behavior of the system with the single membrane and the system with both open-cell and closed-cell membranes. During the first $10 \mathrm{~h}$, the plot does not show an apparent change in the weight, which represents the permeation phase where the opencell membrane has the capacity to absorb water-vapor until saturation. Next, the diffusion of the water vapor towards the closed-cell membrane happens until saturation. Finally, the desorption occurs where the loss of weight is presented.

Since the purpose of the double-layer membrane is to avoid flooding at the gas diffusion membrane, the focus of the plot is in the phase of permeation (i.e., first $10 \mathrm{~h}$ ), where the open-cell membrane is saturated before allowing the water-vapor to pass towards the second layer. The results show a remarkable decrease in the loss of water for the system with the double-membrane. The combination of the high swelling capacity of the open-cell membrane and the hydrophilicity properties of TPU allowed the system to decrease the water loss even at $50{ }^{\circ} \mathrm{C}$, which represents an extreme environmental condition for the battery. 

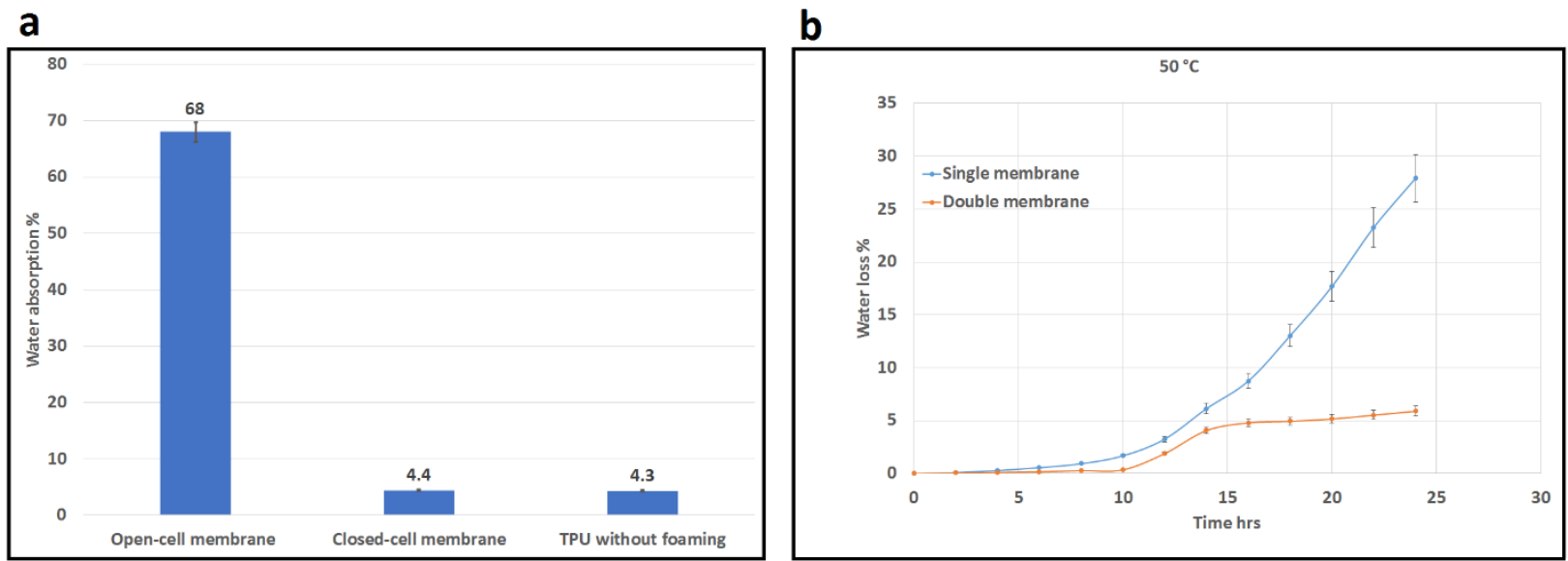

Figure 7. Swelling capacity and MVTR a) Comparison of the swelling capacity between the open-cell foam, closedcell foam, and composite without foaming; b) Comparison of water loss during $24 \mathrm{~h}$ at $50{ }^{\circ} \mathrm{C}$ using only closed-cell and double-layer membranes

\subsection{Electrochemical test}

Figure 8 presents the electrical conductivity for both polymer membranes individually and for the composite without the foaming technique in a frequency between $0 \mathrm{~Hz}$ and $300 \mathrm{kHz}$. The graphic shows a good and stable curve in both morphologies: $4.5 \times 10^{-3} \mathrm{~S} \mathrm{~cm}^{-1}$ for the closed-cell membrane and $9 \times 10^{-3} \mathrm{~S} \mathrm{~cm}^{-1}$ for the open-cell membrane. Also, the conductivity of the open-cell foam is almost the same as the electrode without foaming. This is a result of the foam expansion ratio, the cell density, and the architecture produced by the open-cell morphology, resulting in an aligned orientation of the fillers and the space reduced between the matrix and the fillers. Therefore, the percolation threshold of the MWCNTs and the AC is reduced, maintaining the electrical conductivity as high as the electrode before being foamed. 


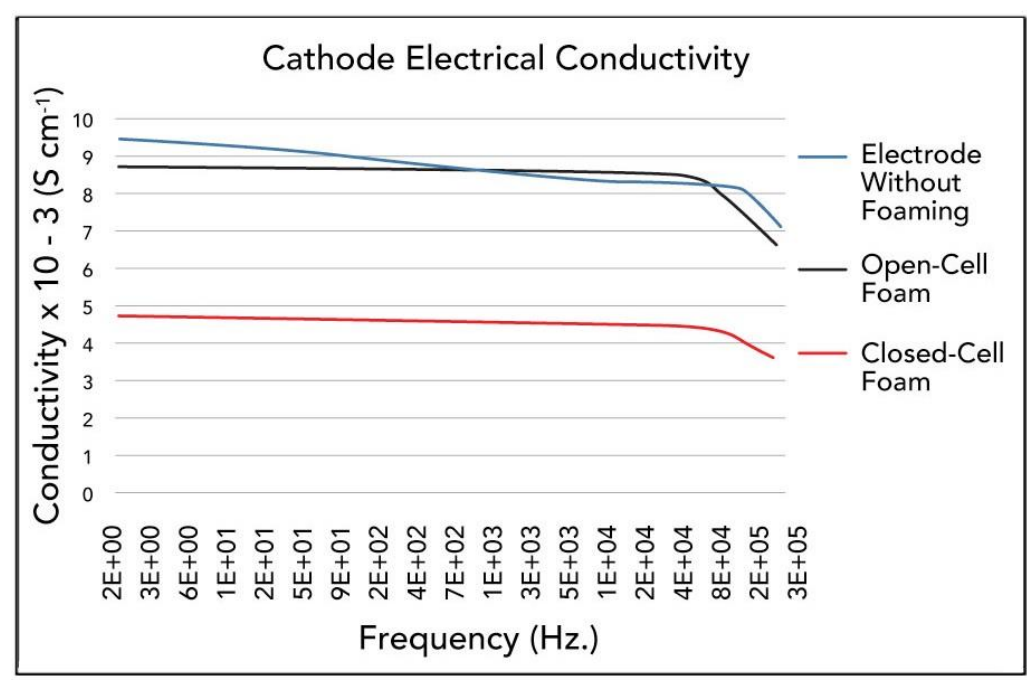

Figure 8. Comparison of the electrical conductivity for the open and closed-cell foam with respect to the electrode without foaming

Figure 9a shows a discharge rate of $0.1 \mathrm{~mA}$ for the aluminum and zinc metal sheets and $1 \mathrm{~mA}$ for zinc. The aluminum battery worked for about $19 \mathrm{~h}$ with a flat discharge curve, whereas the zinc metal cell at a $0.1 \mathrm{~mA}$ discharge rate lasted for about $23 \mathrm{~h}$ before the voltage dropped below the cut-off voltage $(0.8 \mathrm{~V})$. At $1 \mathrm{~mA}$ of discharge, the zinc battery least for $7 \mathrm{~h}$. After the electrochemical tests were done, the cells were disassembled to detect any sign of moisture in the gas diffusion membrane due to leakage. The external membrane did not present any change in dimensions or weight. However, the internal hydrophilic membrane was found with an increment of $10 \%$ of its initial weight, which can be attributed to the electrolyte absorption. The anode was found to be almost completely consumed in the case of $\mathrm{Al}$, and zinc oxide layer formation was found on the metal surface for the $\mathrm{Zn}$ cell.

To increase the surface area between the anode and the electrolyte during the second test, the $\mathrm{Zn}$ metal foil was replaced by $\mathrm{Zn}$ powder with a stainless-steel film as the current collector. 
a
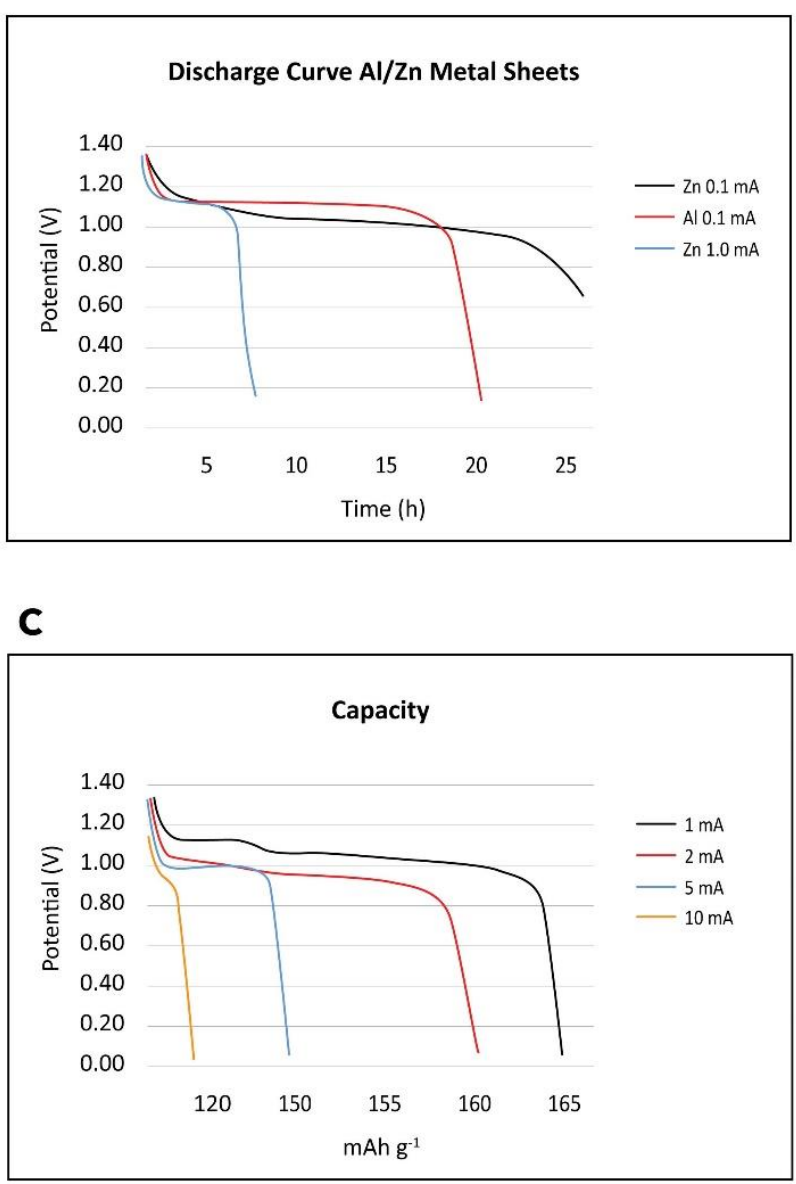

b

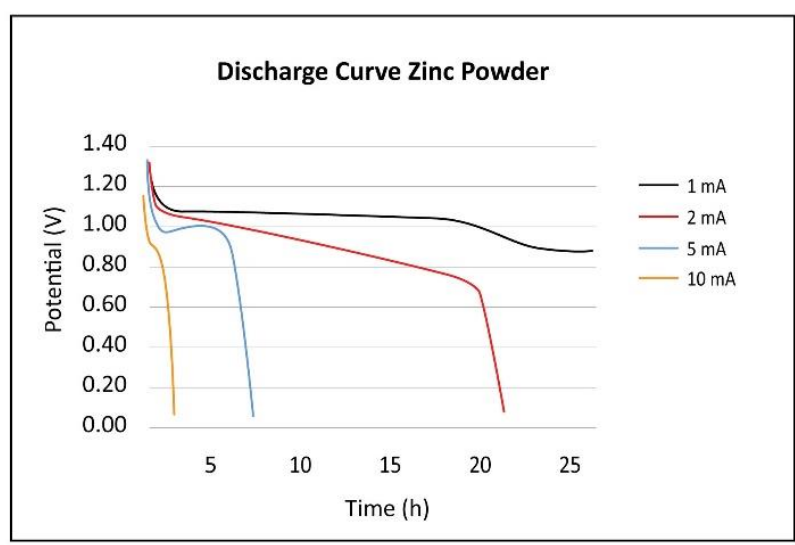

d

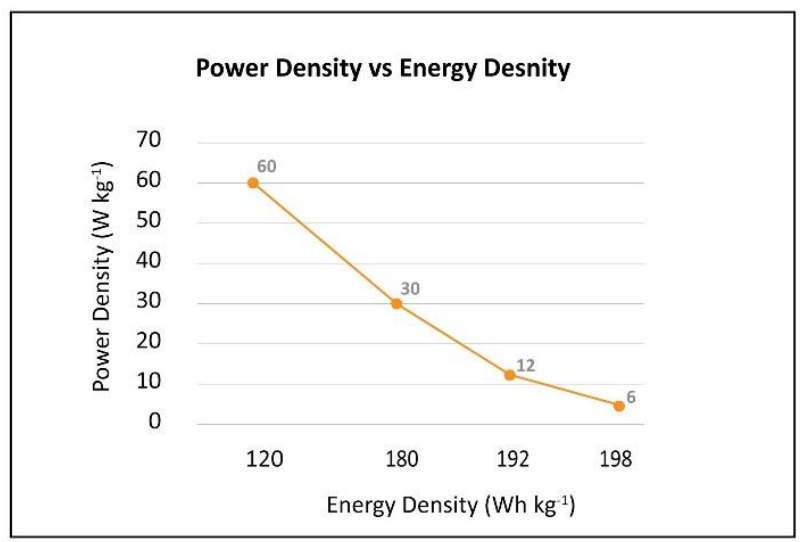

Figure 9. a) Discharge curve for Aluminum and Zinc sheet metal anode; b) Discharge curve for zinc powder at 1 $\mathrm{mA}, 2 \mathrm{~mA}, 5 \mathrm{~mA}$ and $10 \mathrm{~mA}$; c) Capacity of the battery at $1 \mathrm{~mA}, 2 \mathrm{~mA}, 5 \mathrm{~mA}$ and $10 \mathrm{~mA}$; d) Specific power density vs energy density

Figures 9b, 9c, and 9d present the discharge, capacity, and power density curves for the powder zinc-air battery at four different current rates: $1 \mathrm{~mA}, 2 \mathrm{~mA}, 5 \mathrm{~mA}$, and $10 \mathrm{~mA}$. The four rates show stable performance over time. For $1 \mathrm{~mA}$, the cell worked for more than $30 \mathrm{~h}$ and achieved an energy density of about $198 \mathrm{~W} \mathrm{~h} \mathrm{~kg}^{-1}$ before the cell dropped below the cut-off voltage. The higher power density reached is $60 \mathrm{~W} \mathrm{~kg}^{-1}$ at $10 \mathrm{~mA}$ of discharge. However, the amount of active material used (0.2 g) and the lack of additives to suppress the hydrogen evolution could affect the achieved power density. 
After the second tests, both membranes were analyzed. Just like in the previous analysis, no change in weight or dimension was detected for the gas diffusion membrane, even after $33 \mathrm{~h}$ of being tested in a room with relative humidity ranging from $85 \%$ to $90 \%$. Furthermore, it is important to highlight that the results presented in this work were obtained using pure zinc and aluminum metals for the anode and KOH/PVA for the electrolyte. However, previous studies have shown significant improvement for the anode utilization and corrosion inhibition by the use of materials like $\mathrm{Zn}$ alloys and/or metal oxides, and additives for the electrolyte, such as silicates, surfactants, or polymers [32-35].

To test the batteries in real applications, a 1.8 V LED was powered. Two flexible zinc-air batteries using $0.4 \mathrm{~g}$ of zinc and the double-membrane as air-cathode were connected in series; they achieved $3.0 \mathrm{~V}$ in open-circuit voltage, allowing the LED to work for more than $24 \mathrm{~h}$ at a drain rate of $5 \mathrm{~mA}$ (Figure 10a). Also, a single cell was used to power a clock (whose alarm was used every day to simulate regular use) for more than a month. In both cases, no leakage was presented even during bending.

Figure $10 \mathrm{~b}$ also shows the air-battery fabricated under flexion, which can be compared with the concept shown in Figure 1.

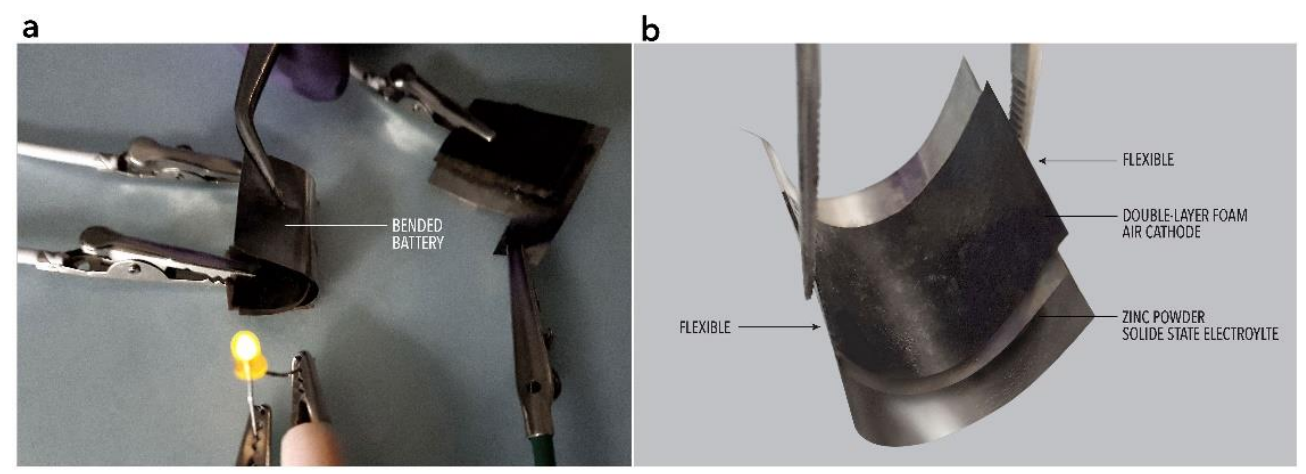

Figure 10. a) Two flexible zinc-air batteries connected in series powering a LED (1.8v) for $28 \mathrm{~h}$; b) Flexible zinc-air battery 


\section{Conclusion}

This paper focused on the fabrication of a novel double-layer composite membrane for its use as an air-cathode for portable and flexible $\mathrm{Zn} / \mathrm{Al}$-air batteries with an aqueous electrolyte. This membrane was produced with the goal to reduce the water loss in the electrolyte under high humidity levels. High flexibility was achieved due to the TPU matrix, whereas the AC and MWCNT produced high electrical conductivity. The double-membrane was designed with different pore morphologies — an open-cell membrane to increase hydrophilicity and water absorption and a closed-cell membrane for hydrophobicity and gas diffusion. The open-cell membrane showed high swelling capacity $(68 \%)$ due to the interconnected channels within the TPU matrix. On the other hand, the closed-cell membrane presented similar stable behavior as the gas diffusion layer for all tests. The battery was assembled with the polymer double-layer cathode and tested under standard temperature/pressure conditions and relative humidity ranging from $85 \%$ to $90 \%$. The specific energy achieved was as high as $198 \mathrm{~W} \mathrm{~h} \mathrm{~kg}^{-1}$ at a discharge rate of $1 \mathrm{~mA}$ for $33 \mathrm{~h}$, whereas the specific power density was as high as $60 \mathrm{~W} \mathrm{~kg}^{-1}$ at a discharge rate of $10 \mathrm{~mA}$ lasting for $2 \mathrm{~h}$. All the tests were performed without any leakage from the battery surface during or after the process - even during bending. Further analysis and electrochemical tests under different humidity and temperature conditions, as well as the $\mathrm{CO}_{2}$ effect, are required in order to verify the effectiveness of the double-membrane air-cathode. 


\section{References}

[1] S.Y. Hong, Y. Kim, Y. Park, A. Choi, N.-S. Choi, K.T. Lee, Charge carriers in rechargeable batteries: Na ions vs. Li ions, Energy Environ. Sci. 6 (2013) 2067-2081. doi:10.1039/c3ee40811f.

[2] J.S. Lee, S.T. Kim, R. Cao, N.S. Choi, M. Liu, K.T. Lee, J. Cho, Metal-air batteries with high energy density: Li-air versus Zn-air, Adv. Energy Mater. 1 (2011) 34-50. doi:10.1002/aenm.201000010.

[3] F. Cheng, J. Chen, Metal-air batteries: from oxygen reduction electrochemistry to cathode catalysts, Chem. Soc. Rev. 41 (2012) 2172. doi:10.1039/c1cs15228a.

[4] L.D. Chen, J.K. Nørskov, A.C. Luntz, Al-air batteries: Fundamental thermodynamic limitations from first-principles theory, J. Phys. Chem. Lett. 6 (2015) 175-179. doi:10.1021/jz502422v.

[5] Q. Liu, Y. Wang, L. Dai, J. Yao, Scalable Fabrication of Nanoporous Carbon Fiber Films as Bifunctional Catalytic Electrodes for Flexible Zn-Air Batteries, Adv. Mater. 28 (2016) 3000-3006. doi:10.1002/adma.201506112.

[6] L. Dumee, L. Velleman, K. Sears, M. Hill, J. Schutz, N. Finn, M. Duke, S. Gray, Control of porosity and pore size of metal reinforced carbon nanotube membranes, Membranes (Basel). 1 (2010) 25-36. doi:10.3390/membranes1010025.

[7] X. Wang, K. Wen, Y. Song, L. Ye, K.H.L. Zhang, Y. Pan, W. Lv, Y. Liao, W. He, Gas transport evaluation in lithium-air batteries with micro/nano-structured cathodes, J. Power Sources. 274 (2015) 762-767. doi:10.1016/j.jpowsour.2014.10.117.

[8] G.M. Wu, S.J. Lin, C.C. Yang, Alkaline Zn-air and Al-air cells based on novel solid PVA/PAA polymer electrolyte membranes, J. Memb. Sci. 280 (2006) 802-808. doi:10.1016/j.amjmed.2006.02.005.

[9] L. Ye, X. Wang, W. Lv, J. Fei, G. Zhu, Y. Liang, Y. Song, J. Zhai, W. He, Analytical insight into the oxygen diffusion in wetted porous cathodes of Li-air batteries, Energy. 93 (2015) 416-420. doi:10.1016/j.energy.2015.09.054.

[10] Y. Li, H. Dai, Recent advances in zinc-air batteries, Chem. Soc. Rev. 43 (2014) 5257-5275. doi:10.1039/C4CS00015C.

[11] X. Ge, A. Sumboja, D. Wuu, T. An, B. Li, F.W.T. Goh, T.S.A. Hor, Y. Zong, Z. Liu, Oxygen Reduction in Alkaline Media: From Mechanisms to Recent Advances of Catalysts, ACS Catal. 5 (2015) 4643-4667. doi:10.1021/acscatal.5b00524.

[12] A. Bakkar, V. Neubert, Corrosion characterisation of alumina-magnesium metal matrix composites, Corros. Sci. 49 (2007) 1110-1130. doi:10.1016/j.corsci.2006.07.002.

[13] A.M. Abdel-Gaber, E. Khamis, H. Abo-Eldahab, S. Adeel, Novel package for inhibition of aluminium corrosion in alkaline solutions, Mater. Chem. Phys. 124 (2010) 773-779. doi:10.1016/j.matchemphys.2010.07.059.

[14] M. Pino, C. Cuadrado, J. Chacón, P. Rodríguez, E. Fatás, P. Ocón, The electrochemical characteristics of commercial aluminium alloy electrodes for Al/air batteries, J. Appl. Electrochem. 44 (2014) 1371-1380. doi:10.1007/s10800-014-0751-6.

[15] Z. Zhang, C. Zuo, Z. Liu, Y. Yu, Y. Zuo, Y. Song, All-solid-state Al-air batteries with polymer alkaline gel electrolyte, J. Power Sources. 251 (2014) 470-475. 
doi:10.1016/j.jpowsour.2013.11.020.

[16] N. Imanishi, O. Yamamoto, Rechargeable lithium-air batteries: Characteristics and prospects, Mater. Today. 17 (2014) 24-30. doi:10.1016/j.mattod.2013.12.004.

[17] M. Xu, D.G. Ivey, Z. Xie, W. Qu, Rechargeable Zn-air batteries : Progress in electrolyte development and cell con fi guration advancement, 283 (2015) 358-371. doi:10.1016/j.jpowsour.2015.02.114.

[18] M. Yousaf, H.T.H. Shi, Y. Wang, Y. Chen, Z. Ma, A. Cao, H.E. Naguib, R.P.S. Han, Novel Pliable Electrodes for Flexible Electrochemical Energy Storage Devices: Recent Progress and Challenges, Adv. Energy Mater. (2016) 1-23. doi:10.1002/aenm.201600490.

[19] C.N. Chervin, J.W. Long, N.L. Brandell, J.M. Wallace, N.W. Kucko, D.R. Rolison, Redesigning air cathodes for metal - air batteries using $\mathrm{MnO}$ x -functionalized carbon nanofoam architectures, J. Power Sources. 207 (2012) 191-198. doi:10.1016/j.jpowsour.2012.01.146.

[20] F. Meng, H. Zhong, D. Bao, J. Yan, X. Zhang, In Situ Coupling of Strung Co4N and Intertwined N-C Fibers toward Free-Standing Bifunctional Cathode for Robust, Efficient, and Flexible Zn-Air Batteries, J. Am. Chem. Soc. 138 (2016) 10226-10231. doi:10.1021/jacs.6b05046.

[21] Y. Bin Yin, J.J. Xu, Q.C. Liu, X.B. Zhang, Macroporous Interconnected Hollow Carbon Nanofibers Inspired by Golden-Toad Eggs toward a Binder-Free, High-Rate, and Flexible Electrode, Adv. Mater. (2016) 7494-7500. doi:10.1002/adma.201600012.

[22] B. Sun, B. Wang, D. Su, L. Xiao, H. Ahn, G. Wang, Graphene nanosheets as cathode catalysts for lithium-air batteries with an enhanced electrochemical performance, Carbon N. Y. 50 (2011) $727-$ 733. doi:10.1016/j.carbon.2011.09.040.

[23] R. Cao, J.S. Lee, M. Liu, J. Cho, Recent progress in non-precious catalysts for metal-air batteries, Adv. Energy Mater. 2 (2012) 816-829. doi:10.1002/aenm.201200013.

[24] M. Kannan, S.S. Bhagawan, S. Thomas, K. Joseph, Nanoclay effect on transport properties of thermoplastic polyurethane/polypropylene (TPU/PP) blends, J. Polym. Res. 20 (2013). doi:10.1007/s10965-013-0201-x.

[25] W. Wohlleben, M.W. Meier, S. Vogel, R. Landsiedel, G. Cox, S. Hirth, Ž. Tomović, Elastic CNTpolyurethane nanocomposite: synthesis, performance and assessment of fragments released during use., Nanoscale. 5 (2013) 369-80. doi:10.1039/c2nr32711b.

[26] X.G. Zhang, Fibrous zinc anodes for high power batteries, J. Power Sources. 163 (2006) 591-597. doi:10.1016/j.jpowsour.2006.09.034.

[27] E. Richards, Æ.R. Rizvi, Æ.A. Chow, Biodegradable Composite Foams of PLA and PHBV Using Subcritical CO 2, (2008) 258-266. doi:10.1007/s10924-008-0110-y.

[28] Y. Ito, M. Yamashita, M. Okamoto, Foam Processing and Cellular Structure of PolycarbonateBased Nanocomposites, (2006) 773-783. doi:10.1002/mame.200600075.

[29] F. Al Jahwari, A.A.W. Anwer, H.E. Naguib, Fabrication and microstructural characterization of functionally graded porous acrylonitrile butadiene styrene and the effect of cellular morphology on creep behavior, J. Polym. Sci. Part B Polym. Phys. 53 (2015) 795-803. doi:10.1002/polb.23698.

[30] Y. Yuan, T.R. Lee, Contact Angle and Wetting Properties, 2013. doi:10.1007/978-3-642-34243-1.

[31] S.H. Ajili, N.G. Ebrahimi, M.T. Khorasani, Study on Thermoplastic Polyurethane / Polypropylene ( TPU / PP ) Blend as a Blood Bag Material, (2002). 
[32] X. Zhang, X.-G. Wang, Z. Xie, Z. Zhou, Recent progress in rechargeable alkali metal-air batteries, Green Energy Environ. 1 (2016) DOI: 10.1016/j.gee.2016.04.004. doi:10.1016/j.gee.2016.04.004.

[33] Z. Feng, L. Ren, J. Zhang, P. Yang, M. An, RSC Advances E ff ect of additives on the corrosion mechanism of nanocrystalline zinc - nickel alloys in an alkaline bath, RSC Adv. 6 (2016) 8846988485. doi:10.1039/C6RA18476F.

[34] T.K.A. Hoang, T. Nam, L. Doan, K. Eun, K. Sun, P. Chen, RSC Advances potential use in rechargeable aqueous batteries, RSC Adv. 5 (2015) 41677-41691. doi:10.1039/C5RA00594A.

[35] K. Wongrujipairoj, L. Poolnapol, A. Arpornwichanop, S. Suren, S. Kheawhom, Suppression of zinc anode corrosion for printed flexible zinc-air battery, 6 (2016) 1-6. doi:10.1002/pssb.201600442. 